\title{
BMJ Open 'He's going to be a doctor in August': a narrative interview study of medical students' and their educators' experiences of aligned and misaligned
assistantships
}

\author{
Owen Meurig Jones, ${ }^{1}$ Chiemeka Okeke, ${ }^{2}$ Alison Bullock, ${ }^{3}$ Stephanie E Wells, ${ }^{4,5}$ \\ Lynn V Monrouxe ${ }^{6}$
}

To cite: Jones OM, Okeke C, Bullock $A$, et al. 'He's going to be a doctor in August': a narrative interview study of medical students' and their educators' experiences of aligned and misaligned assistantships. BMJ Open 2016;6: 011817. doi:10.1136/bmjopen-2016011817

- Prepublication history for this paper is available online. To view these files please visit the journal online (http://dx.doi.org/10.1136/ bmjopen-2016-011817).

Received 15 March 2016 Revised 2 May 2016 Accepted 9 May 2016

\section{CrossMark}

\section{${ }^{1}$ Cardiff University School of Medicine, University Hospital of Wales, Cardiff, UK \\ ${ }^{2}$ Cardiff University School of Medicine, Cardiff, UK ${ }^{3}$ CUREMeDE, Cardiff University School of Social Sciences, Cardiff, UK ${ }^{4}$ Wales Deanery, Cardiff, UK ${ }^{5}$ Cardiff University, Cardiff, UK \\ ${ }^{6}$ Chang Gung Medical Education Research Centre, Linkou, Taiwan}

Correspondence to Dr Lynn V Monrouxe; monrouxe@cgmh.org.tw

\section{ABSTRACT}

Objective: To explore final-year students' and clinical supervisors' experiences of alignment and misalignment with future Foundation Year 1 (F1) posts in an assistantship programme in the UK.

Setting: Assistantships are clinical placements in which students assist junior doctors by undertaking similar duties under supervision. Models of assistantship programmes vary across curricula. Some actively seek to align with students' initial postgraduate F1 post. To date, no research has examined the implications of this association for teaching and learning. Qualitative individual and group narrative interviews were conducted with students and supervisors of 2 Welsh medical schools to address: RQ1: How do students and supervisors understand the purpose of the longitudinal assistantship? RQ2: Does alignment/misalignment of the assistantship with students' initial F1 post influence students' and supervisors' teaching and learning experiences? Audiorecordings of interviews were transcribed, participants anonymised and framework analysis was used.

Participants: A convenience sample of 4 participant groups comprised (1) final-year medical students whose assistantship and F1 post were aligned $(n=27)$, (2) final-year medical students whose assistantship and $F 1$ post were misaligned $(n=18)$ and (3) supervisors ( $n=10$, junior doctors; $n=11$, consultants). Results: All participant groups highlighted increased student confidence in undertaking the duties of an F1 doctor arising from their assistantship period. Learning transferable skills was also highlighted. Many students considered themselves to be team members, "learning the trade' as they shadowed their F1. Opportunities for caring for acutely unwell patients were scarce. The evidence shows enhanced engagement for students aligned to their first F1 post with greater opportunities for workplace acclimatisation. Those who were misaligned were perceived as being disadvantaged. Conclusions: Our findings suggest that alignment with students' first F1 post enhances the assistantship experience. Further longitudinal assessment is required to examine whether and how this translates into

\section{Strengths and limitations of this study}

- This is the first research article (to the authors' knowledge) to explore the value of assistantship alignment through interviews with students who had their placements aligned $(n=27)$ and misaligned $(n=18)$ to their future Foundation Year 1 (F1) posts, in addition to their supervisors $(n=21)$.

- The large sample of student participants $(n=45)$ includes those in diverse clinical settings, based at 10 different hospital sites across a single UK country.

- Participants were interviewed during the assistantship period, to capture their experiences as they happened.

- As participants were interviewed during the assistantship period, views represent subjective self-perceptions of alignment, rather than objective knowledge scores. Further studies to assess F1 doctors' perceptions during employment are required to investigate the long-term implications of assistantship alignment.

- The use of convenience sampling could mean that the results represent the views of more motivated individuals.

improvements in functioning and reductions in stress and anxiety during this transitional period.

\section{INTRODUCTION}

Background

Described as Black Wednesday and the August (or July) effect, compromised patient care at the time when newly qualified doctors start work is of international concern $^{1-7}$ and has been evidenced through increased patient mortality rates. ${ }^{3}{ }^{4}$ Indeed, interview and questionnaire studies suggest that junior doctors often feel underprepared 
for practice,,$^{8-12}$ and other healthcare professionals also perceive them as such, ${ }^{9} 1213$ despite preparation for work being a focus of undergraduate medical education policy and practice. $^{9}$ For example, in 2011, the UK General Medical Council's (GMC) National Training Survey found that $24 \%$ of newly qualified doctors felt inadequately prepared to start work as Foundation Year 1 (F1) doctors. ${ }^{14}$ Research has also highlighted specific areas of weakness concerning medical graduates' preparedness in the UK, including prescribing and acute care. ${ }^{915}{ }^{16}$ Data collected by Monrouxe et a $t^{9}$ recently gave insight into the preparedness of UK medical students for the August transition period. Important aspects of practice in which students remain unprepared include safe and legal prescribing, managing complex conditions and providing immediate emergency care. ${ }^{9}$ Furthermore, these feelings of unpreparedness cause junior doctors great distress, something for which they also feel unprepared to manage. ${ }^{9}$

\section{Assistantships to smooth transition to practice}

Opportunities to 'learn on the job', for medical undergraduates to become familiar with the day-to-day roles of a junior doctor, are considered imperative for increasing their preparedness to start work. ${ }^{15} 17{ }^{18}$ Since the publication of 'Tomorrow's Doctors 2009', ${ }^{19}$ all UK medical schools have been required to include a student assistantship in their final-year curriculum. This followed calls for interventions to smooth the student-doctor transition, ${ }^{9} 15$ for example, through opportunities for 'more experiential learning in clinical practice'. ${ }^{15}$ Assistantships have been defined as placements 'in which a student, assisting a junior doctor and under supervision, undertakes most of the duties of an F1 doctor' ${ }^{19}$ In their most recent guidance, the GMC has further emphasised the importance of opportunities for integration within clinical teams and exposure to emergency care settings within student assistantships in order to enhance undergraduates' preparedness. ${ }^{20} 21$

In addition to their student assistantship, students undertake a separate period of paid 'shadowing' after graduation. This comprises $\sim 1$ week, during which they work like an F1 doctor, assisting the specific F1 they will replace. ${ }^{17-19}$ In contrast to the shadowing period, student assistantships are undertaken in the undergraduate setting and typically not in the specific context of students' upcoming work post. They are principally designed to increase students' preparedness to start practice as an F1 generally, whereas the shadowing period aims to familiarise students with the specific site in which they will be immediately working. Nevertheless, some medical schools facilitate an 'aligned' assistantship in the setting of their upcoming F1 posts, in the hope that they might potentially add to students' preparedness for employment. However, as information of clinical rotations for the F1 is not released until early April of the final year, it is difficult for some medical schools to arrange 'aligned' assistantship placements.

\section{Evidence base for the assistantship period}

As student assistantships are relatively new phenomena, there is limited evidence for their efficacy and a lack of examination of different types of assistantship models. ${ }^{9}$ However, available evidence suggests that assistantships do indeed appear to fulfil the promise of increasing medical students' preparedness practically and psychologically. ${ }^{9}{ }^{22-25}$ For example, Van Hamel and Jenner ${ }^{26}$ recently found that while $27.8 \%$ of $\mathrm{F} 1$ doctors screened positive for pathological anxiety shortly after starting work, increased time spent in a 'shadowing' type role, such as student assistantship during medical school, reduced their anxiety levels on starting work. Regarding preparedness, a questionnaire study of 126 students from a single medical school following the completion of a student assistantship found a significant improvement in some areas: the assistantship appeared to fulfil its aim of integrating students into the clinical team and improving aspects of their understanding of the work environment. ${ }^{22}$ Indeed, the literature surrounding preparedness reveals that this workplace familiarity is considered to be an important component of F1 doctors' transition into work, although it is often missing in students' learning opportunities. ${ }^{9}$ This is particularly so for students who commence their first postgraduate post as a doctor within a location that is different to the one in which they trained. As such, the opportunity to become familiar with the new working environment may be restricted to any shadowing period that occurs immediately prior to taking on their new role. In the UK, this presently has a minimum requirement period of 4 days. ${ }^{27}$

Fullbrook et $a l^{24}$ and Lightman $e t a l^{25}$ recently reported evidence that assistantships can be perceived to contribute towards students' preparedness, and reassuringly, they convey that students become part of their clinical team. Importantly, they also shed light on the benefits of assistantship placements being relevant to students' F1 posts. ${ }^{24} 25$ These benefits include developing site-specific competencies when students work in their prospective jobs, such as becoming familiar with the Trust's clinical computer programmes. ${ }^{25}$ Conversely, students perceive assistantships to be less useful when they do not relate to their first F1 post. ${ }^{24}$ Significantly, the degree of responsibility delegated to students appears to be key to the perceived success of the assistantship. ${ }^{24}$ These findings echo recent work by Monrouxe et at who found that the quality of assistantships vary according to individual factors such as students' personal characteristics, as well as contextual factors including leadership, positive role models and the wider team. However, there has been no exploration of whether students' responsibility levels during their assistantship are affected by alignment with their first F1 post.

\section{Problems with existing evidence}

Although research examining the assistantship period is beginning to emerge, studies tend to be limited by relatively low participant numbers for qualitative and 
quantitative studies as well as being restricted to a single medical school. ${ }^{24}{ }^{25}$ As such, transferability of findings is restricted. There is also a lack of qualitative exploration of supervisors' views of student assistantships, which has been shown to contradict those of students. ${ }^{23}$ Finally, despite highlighting some elements of assistantships that improve preparedness, the findings may not be transferable to all assistantships as assistantship models are variable and poorly defined in both of these studies. Although current qualitative studies have explored assistantship alignment with students' first F1 post, their results do not thoroughly contrast the differences between the experiences of students who undertook placements aligned to their F1 post and those who did not. $^{24}{ }^{25}$ For example, Lightman et $a t^{25}$ report only generic findings under the theme of students' position within their team with no specification of whether this varied with F1 post alignment. As such, current studies do not offer a comprehensive analysis of how F1 alignment affects students' learning experience. ${ }^{24} 25$ Furthermore, Fullbrook $e t a l^{24}$ did not interview participants in assistantships misaligned to their upcoming posts.

\section{Aims and research questions}

We aim to address the current gaps in the literature by qualitatively examining students' and supervisors' engagement with a distinctive longitudinal assistantship model developed by two UK Universities. We believe that such a study can potentially guide educators internationally towards an optimal design and implementation of senior experiential placements, a scheme that is becoming increasingly popular.

This study addresses the following research questions:

1. What are students' and supervisors' conceptualisations of the purpose of the longitudinal assistantship?

2. Does alignment of the longitudinal assistantship with an individual's first F1 post influence their experiences during the placement? If so, how?

\section{METHODS}

\section{Setting}

The research setting comprises the only two medical schools in one UK country (Wales) within which all undergraduate medical students undertake a 6-week to 7-week assistantship immediately before graduation, and prior to undertaking the required 4-day shadowing period in which they observe the existing junior doctor post before undertaking the role themselves. Approximately $66 \%$ of these students subsequently enter the Wales Foundation School ${ }^{28}$ and so have the opportunity to undertake their assistantship aligned with their first F1 post. As such, they effectively complete an extended 8-week shadowing period. The remaining students $(\sim 34 \%)$, who will move outside of Wales for their F1, undertake their assistantships attached to one of the remaining $\mathrm{F} 1$ posts in Wales. This group thus experience only the minimum 4 days of shadowing prior to working in their new post in August. This unique national setting, therefore, provides us with naturally occurring comparator groups within a single country: those who undertake their assistantship attached to their first F1 post and those who do not. We explore the relative value of each from the perspective of students and their clinical supervisors.

\section{Design}

A qualitative narrative interview study underpinned by a social constructionist epistemology was conducted with four distinct participant groups: (1) final-year medical students whose assistantship and F1 were aligned, (2) final-year medical students whose assistantship and F1 were misaligned, (3) junior doctor supervisors and (4) consultant doctor supervisors. This perspective entails that there is no single 'right' version of the truth and that individuals construct their own truths based on experiences and interactions with each other and the social world. Different participants will make different meanings of their experiences, and we as researchers have a role in interpreting these.

The study population comprised all final-year students in Wales. We used non-probabilistic sampling (quota and snowballing) in which participants were recruited via face-to-face announcements during their scheduled teaching (students and trainee doctors), email invitations (all groups) and information posted on social media (students). The opportunity to participate in either a group or one-to-one interview was offered to all. Participant snowballing was achieved through invitation by those already participating (all groups).

\section{Participants}

\section{Student participants}

In total, 45 students participated in 10 focus group interviews and 2 one-to-one interviews. These occurred across 10 different hospitals in 5 regional locations. Nine of the group interviews were homogenous: comprising students experiencing either aligned ( $\mathrm{n}=5$ groups) or misaligned ( $n=4$ groups) assistantships. One group comprised a mix of students due to participant availability.

The aligned participants comprised a total of $n=27$ $(60 \%)$. Of these 27 students, $63 \%(n=17)$ were women. Eighty-one per cent $(n=22)$ were enrolled at Cardiff University and $19 \%(\mathrm{n}=5)$ at Swansea University, representing the differing sizes of the student cohorts. The remaining student participants undertook assistantships not aligned with their first $\mathrm{F} 1$ post and comprised a total $\mathrm{n}=18 \quad(40 \%)$. Of these, $56 \% \quad(\mathrm{n}=10)$ were women. Seventy-two per cent $(n=13)$ were enrolled at Cardiff University and 28\% ( $\mathrm{n}=5)$ at Swansea University.

\section{Supervisor participants}

Ten foundation doctors and 11 consultants were recruited. Foundation doctors participated in either focus groups or individual interviews. Consultants 
participated in individual interviews (due to time constraints). Sixty-two per cent $(n=13)$ of all supervisors were men. Thirty per cent $(n=3)$ of the foundation doctors and $91 \%(n=10)$ of the consultants were men.

\section{Data collection}

Participants were provided with an information sheet in advance of their interview or focus group. Prior to commencing the focus group or interview, written consent was obtained. All focus groups and individual interviews were audio-recorded with the permission of each participant. Following training sessions in narrative interview techniques (LVM, AB), focus groups and interviews were conducted by either the first or second author (OMJ, $\mathrm{CO})$. All participants were aware that the interviewers $(\mathrm{OMJ}, \mathrm{CO})$ were third-year medical students undertaking the study as part of a student selected component project. Interviews were conducted with student participants in tutorial rooms based in the hospital where they were undertaking their assistantship. Supervisor participants were interviewed either in the office of the principal investigator or in their own office. All interviews took place in confidential, quiet rooms. Participants were informed via information sheets of all researchers who were part of the research team and who would have access to the data. A discussion guide was used for the interviews as a memory aid and as a flexible topic guide, resulting in a semistructured interview. Each interview or focus group began with the orienting question around defining assistantships. Following this, participants were asked to tell us about their assistantship experiences. The use of a narrative interviewing technique alongside the topic guide provided the additional benefit of uncovering descriptions of unanticipated experiences. The interviewers made brief notes after interviews as a memory aid for subsequent interviews and to help inform development of a thematic framework.

\section{Data analysis}

Group interviews with students were 1-1.5 hours, and individual interviews were $30-60 \mathrm{~min}$ in length. Audio-recordings were transcribed and participants anonymised. All authors conducted the framework analysis $^{29}$ inductively using the following steps: authors became familiar with a subset of the transcripts with each transcript being read by at least two researchers; themes were identified individually; authors came together, discussed and negotiated their themes; an index of these themes and relevant subthemes were constructed with any disagreements being negotiated until agreements were reached; data were coded using ATLAS-ti (V.7.5.6) according to the framework and themes were added or amended as necessary during further group discussions. Each transcript was coded by either the first or second named author (OMJ, CO). At least $20 \%$ of the data were double-checked for reliability. Any disagreements surrounding appropriate codes were discussed and negotiated, and a final code was settled on by the authors.

\section{RESULTS}

Four main themes and associated subthemes were identified: (1) definitions of assistantship, (2) students as team members, (3) opportunities for learning and (4) engagement and identities. We discuss each theme in turn below with excerpts from participants' interviews to evidence our findings. Each excerpt is labelled with a unique participant identifier. The abbreviations used are as follows: $\mathrm{M}=$ Male; $\mathrm{F}=$ Female; $\quad \mathrm{S}=$ Student; $\quad \mathrm{SP}=$ Consultant supervisor; F1=Foundation doctor supervisor; Aligned=assistantship in same setting as F1 post; Misaligned=assistantship in different setting to F1 post; \#=participant number, for example, F_S_Aligned_1=female student in an aligned placement (participant 1).

\section{Theme 1: definitions of assistantship}

We identified three subthemes arising from students' and supervisors' responses to our opening interview question regarding how they conceptualised the assistantship. Assistantships were described as opportunities for learning the trade, as providing a transitional bridge and as placements that were August-focused.

\section{Learning the trade}

Irrespective of alignment, the majority of students defined the student assistantship as a process of understanding the role of a doctor. This contrasted with their experiences as undergraduates during which time they had become familiar with theoretical-rather than practical-aspects of medicine. Students described how their knowledge of the roles and duties of an F1 had developed throughout the assistantship and valued the new insights they were gaining into what would be expected of them as a F1 doctor:

In the other placements I guess it's been more about having to learn actual medicine. Whereas now, it's 'I need to learn to be an $\mathrm{F}^{\prime}$, which $\mathrm{I}$ think is different to learning medicine. (F_S_Aligned_3)

All students and supervisors recognised the value of having opportunities to learn and develop practical skills required of a F1 doctor. Such opportunities were perceived as valuable regardless of assistantship-F1 alignment. Formal teaching sessions and assessments during the assistantship were generally perceived as barriers to learning the trade, by students and supervisors. However, certain teaching sessions were valued by students, including sessions on topics such as prescribing. Nevertheless, most students generally valued having the freedom to pursue their own ward-based learning and felt that formal teaching consumed time that could be more productively spent shadowing their F1. 


\section{A transitional bridge}

A smaller proportion of students (in aligned and misaligned groups) described the purpose of the student assistantship as smoothing the transition between medical student and junior doctor, which in turn served to relieve their anxieties about becoming a junior doctor. This view was also expressed by a small number of consultant supervisors who saw the assistantship as a means of minimising the jump in responsibility associated with becoming a doctor.

\section{August-focused}

Students and supervisors described preparation for the first post following graduation as a central aim of the student assistantship. However, differences were observed here between students in the aligned group versus those in the misaligned group. Students in the misaligned group viewed the assistantship as a general preparation for their F1 role, whereas those in the aligned group highlighted the importance of assistantships in facilitating workplace acclimatisation. These students highly praised the opportunity to become familiar with their ward, hospital and local protocols. They valued the time spent getting to know their future colleagues. For many, this process relieved some of their anxieties about starting work in August:

The Assistantship is the opportunity for us as final medical students to get to grips with the day-to-day tasks and knowledge of being the F1 which is something particularly applicable if you're shadowing your own job. So finding out what they do in practical terms on a day-to-day basis so that we can be ready for that when it becomes our role in August. (F_S_Misaligned_34)

Many supervisors (consultants and F1 doctors) also expressed their belief that assistantships aligned with the first F1 post increased students' preparedness. Consultant supervisors had experience of supervising students who were staying and those who were leaving (over the course of 3 years) and therefore were able to draw this conclusion. Many F1s drew on their personal experience of undertaking an aligned assistantship to express this view, if not from observing their student. Conversely, some students in the misaligned group highlighted a reluctance to become familiar with certain aspects of the workplace, as they perceived that their effort would not yield a benefit for August:

I mean, there has been a few times when I... I mean it's not been big things, but it's stuff like pulling up $\mathrm{x}$-rays which you do all the time. They were going to show me how to sign in and sign out and then they were like, 'actually it doesn't really matter if you're not staying because you don't really need to know', which is true. I don't need to know. I'm not staying and things will be different...but they do skim over a lot of stuff because there is no point in you knowing. (F_S_Misaligned_16)
Theme 2: students as team members

This theme captures facilitators and barriers to integrating students into the clinical team during the assistantship. We report on these aspects as we present the four subthemes of becoming functional team members, becoming socially integrated, feeling excluded and students as side-kicks.

\section{Becoming functional team members}

All students and supervisors frequently expressed that students adopted a genuinely useful role within their team. This involved performing tasks such as clerking patients and shadow-prescribing, supervised learning events in which students propose and write prescriptions for patients that are subsequently checked and signed by a doctor before their administration. These contributions were valued by other team members, as reflected by students receiving thanks for their work at the end of the day. Students within the aligned group more often expressed this sense of becoming a functional team member. These experiences, on occasion, may have been reinforced by consultant supervisors who admitted to giving more tasks to the students they knew would be taking over that particular role in August as they wanted them to have a good grounding:

I think the F1s really appreciate your help now. They know they can, kind of, maybe rely on you a bit more to be able to just go off and do stuff. I think that's definitely, like my F1 got me to do ward cover with him on Bank holiday Monday, but I think it was probably... it was really useful for me to see that as well, but he was able to send me off and go and like review patients and, like, let him know how they were. Whereas that's been quite useful. So it is like he makes you feel like part of the team. (F_S_Misaligned_9)

So I was like an hour late for work because of traffic. So I texted my student from my car, very legally, and asked him to start with the MDT [multidisciplinary team] prep. So that involves talking to one of the nursing staff. Getting all the notes. Checking with the physios with the lung functions. Updating our list. Getting everything together. There's quite a lot of jobs and then arranging the charts and by the time I got there, like an hour later everything was done. So he couldn't have done that if he couldn't work in the team, and there were a few things he didn't know how to do but he managed. (F_F1_46, Student in an aligned placement)

It's impossible not to think 'Yes but they are not staying here'. Emotionally you have already, not disinvested...but you are not going to reap the benefits of what you are going to achieve. (M_SP_54, Student in misaligned placement)

\section{Becoming socially integrated}

Student groups and supervisors expressed a sense of social integration between students and their team during their assistantship. They described joining their 
team for coffee after the ward round or going out for drinks to mark the end of the assistantship:

Yeah, you go with them for coffee and you don't lose them. Whereas, you know, in other years I'd go to the common room instead. (F_S_Misaligned_41)

In addition, some consultants supervising students in the aligned group described how they had expressed a greater interest in the students' career goals and a few organised projects for them to undertake during their F1 year.

\section{Feeling excluded}

Although a rare occurrence, students gave accounts of feeling that they were not useful members of their team. This sometimes occurred legitimately on grounds of patient safety. For example, re-clerking patients after the student had clerked them. On occasion, supervisors justified not giving students additional responsibilities to avoid making the student feel out of their depth. However, some students gave accounts of situations where they felt they had been unfairly excluded, for example, team members failing to learn a student's name or failing to give them reasonable levels of responsibility. Some students in the aligned group described instances where team members began to warm to them once they understood that they would be joining their team:

I don't think my consultant knows my name, but she knows the girl that's staying, her name, and I got her 'Who's doing the TTH [discharge summary]? Her, that medical student.' (F_S_Misaligned_24)

\section{Students as side-kicks}

This subtheme comprises students' colourful talk around taking on the responsibility of carrying out the menial or routine tasks on the ward on behalf of the team. Often this is something that the students joked about as they defined themselves as servants, using synonyms such as skivvy, bitch, minion or side-kick. In contrast, supervisors made such comments very rarely to the same effect. This entitlement was often seen as a beneficial experience or a prerogative rather than undesirable or unjust. Students felt positive about taking workload off the team, for which they were thanked, and being referred to as an 'extra pair of hands' lead them to feel more like active team members:

I think to begin with you are very much, sort of, a tea lady in a sense. You know go and fetch the notes. Go and check this. Like you don't really do proper jobs, but then I think as they trust you a bit more and get to know your knowledge base they trust you as more of a member of the team. (F_S_Aligned_22)

\section{Theme 3: opportunities for learning}

Participants discussed the factors that influenced students' educational gain during their assistantship. Learning opportunities that enabled students to develop confidence and take responsibility were valued. However, barriers to learning were described with reference to assistantship organisation, the scarcity of acute care experience and supervisors' lack of awareness of the assistantship aims. We discuss the three subthemes of developing confidence, responsibility and organisational barriers to learning.

\section{Developing confidence}

Both groups of students described undertaking tasks that allowed them to gain confidence in their ability to undertake the duties of an F1 doctor. These included proposing management decisions (such as shadowprescribing), performing administrative tasks and undertaking practical procedures (eg, taking bloods for blood transfusions after completing their blood transfusion competency assessment). Many F1s and consultants also provided vivid examples of students' learning:

And just getting a bit more practice of things that we haven't done before. So that's for taking bloods for blood transfusions, filling in the forms correctly. It's not something we've had that much opportunity to do, but on this placement there is, and you can just do them and then just get them reviewed. I think there were a couple of errors on the first one and then you just redo it. I just feel I'll be confident to do it when I was an F1. (M_S_Misaligned_32)

There was definitely one, where we got a student doing a pleural aspiration...definitely a fairly technically demanding procedure that the student did under supervision, and you then get a real buzz from it. I think we got a buzz because they did... and they did it very well...it [assistantship] breaks down the barriers. It allows them to see what it is like and feel like to do real things to real patients, to experience the anxiety of doing that for the first time, and the next time you do it, it is a little bit easier and a little bit easier again. (M_SP_51; Student in a misaligned placement)

\section{Responsibility}

Most students perceived they were given a level of responsibility that provided adequate preparation for the demands of being an $\mathrm{F} 1$, regardless of $\mathrm{F} 1$ post alignment. This included freedom to complete tasks such as clerking patients, practical procedures (eg, venepuncture) and reviewing test results independently. However, students felt that senior support was at hand should students require reassurance. Most supervisors also perceived that students had appropriate levels of responsibility, while being adequately supervised:

I think it's just generally the people they would have come in contact with on the ward that may have become acutely unwell, so they may have assessed them initially, 
cannulated them, taken blood tests and come up with an initial thought on how to manage that patient, but with the knowledge there is an F1, F2 and more senior support immediately on hand to run through that process with...it is good to be able to do that independently, but have that checked off by a junior doctor. So, you know, there is a degree of supervision there. But at the same time they are able to do it as if they were a junior doctor themselves. (M_SP_53; Student in an aligned placement)

Despite this, many students and foundation doctor supervisors emphasised the distinction between students' role and that of a junior doctor due to the lack of ultimate responsibility for patient care. Some believed that this limited the extent to which students could prepare for the role of an $\mathrm{F} 1$ :

I think there is a lack of responsibility when you're a student, because everything you do needs to be signed off by everyone else. You have to run something past everyone else, so you do force yourself to make decisions. You can kind of say 'Oh this is what I think', but somebody else has to decide. That is the big jump when you come up to F1, it is all of a sudden nobody to run those things past. You just have to make those calls for yourself and you can never give somebody a taste of that responsibility all the time that they are not allowed to have it. So, within the confines of what is allowed, it is gives them the maximum responsibility they can have, but ie, the main barrier. (F_F1_61; Student in a misaligned placement)

Very infrequently, students from both groups discussed situations in which they were given little or no responsibility, such as not doing reasonable tasks expected of an F1. For example, writing in patient notes. More commonly, consultants highlighted students' general reluctance to take on responsibility. This behaviour was often attributed to students' lack of confidence. F1s expressed this view less commonly. Similarly, students from both groups occasionally highlighted situations in which they avoided potential opportunities to take responsibility, for example, when given the opportunity to complete the initial assessment of a patient:

I had one very ill patient who sort of deteriorated quite quickly and conveniently the F1 and the SHO [senior house officer] sort of magically disappeared and I was just like, oh there is a sick patient and I'm expected to do something right now and sort of flapped around a little bit and did nothing, and then they arrived. So, I don't know, I'm sort of there. Just not quite. (M_S_Aligned_4)

Alternatively, students rarely described having no difference between their level of responsibility and that of an F1 doctor. Thus some students and supervisors described instances where students were left to fill in the role of the F1 doctor on the ward single-handedly, in the absence of their supervising F1 but under appropriate senior supervision. Students in the aligned group more frequently discussed this, along with their supervisors:

Yes. I mean, they certainly did take on the role of an F1 and there were a couple of days when the F1 was away and they actually stepped into the F1s role. So that was I think for them quite useful, but yes, I mean, we sort of kept it at the F1. There are times when the F1 ends up being, you know, the F2, the Registrar and the consultant, you know, there are times when they're on their own, but yeah at this point they were supported with a $\mathrm{SHO}$ and a Registrar most of the time. So I think it was really just stepping into the F1 role on a couple of days when the F1 was away. That was probably useful, yes. (M_SP_62; Student in an aligned placement)

Concerning patient safety, such quotes highlight the importance of ensuring that students are adequately supervised at all times.

\section{Organisational barriers to learning}

Certain organisational factors were seen as a barrier to students' learning. This theme was most frequently discussed by students in the misaligned group, particularly concerning failures to match students' assistantships to their first F1 post in terms of specialty:

Yeah, I've had a good placement and a good team and, like I say, Dr X is a great consultant. So from that point of view in terms of just a general placement it's been very good, but as a concept it's really good for these guys, I think it's great. I'm jealous that they get to do the job, you know, for that length of time. I think it would be so much more useful if I got to go to where I'm going be doing my F1 job. So from that point of view overall I wouldn't say it's been that useful. (M_S_Misaligned_11)

Many students conveyed that exposure to the care of critically unwell patients was a rare occurrence during their assistantship, especially the opportunity to attend cardiac arrest calls. As such, both student groups conveyed anxieties concerning such demands. Supervisors similarly believed that the opportunity to manage critically ill patients was specialty-dependent. Many students expressed that they desired the opportunity to carry the cardiac arrest bleep, an opportunity provided to students in one hospital:

I've never actually seen real chest compressions in the whole five years, but I think the simulation training that we've had this year has just helped so much with that. So if that [holding the arrest bleep] was in the assistantship that would be really helpful, I think because it's so close to when you're starting. I mean, we all have to do the ALS [advanced life support] course, but mine is not until September. (F_S_Misaligned_41)

Very rarely, students from both groups perceived that consultants lacked awareness of the student assistantship programme and their competencies. This was reflected in student narratives about supervisors showing their 
disapproval of them carrying out tasks expected of an F1 such as clerking and practical procedures. Indeed, participating consultants occasionally expressed a lack of awareness of the requirements from students during their assistantships, with some suggesting that suitable tasks should be more clearly defined:

Yeah, and actually we had one case the other day where were quite busy so one of the students was given the task of phoning to refer a patient for a review to another team and he's a very competent student and was confident doing it himself, and the person came to review but then actually had a go at me for letting me let one of my medical students refer to him and that was completely inappropriate and my Registrars wouldn't take it and, sort of, went on a bit of a rant at me, and I sort of said, 'well to be honest he's going to be a doctor in August. He's going to be doing this August, like he's going to have to learn'. (F_F1_57; Student in an aligned placement)

\section{Theme 4: engagement and identities}

Students and supervisors discussed the role of the assistantship in the development of students' professional identity and insights into their anxieties and limitations at the start of their transition from student to F1 doctor. We outline the subthemes of increased professional engagement, identity classification and performing identities, tolerating uncertainty and unrelieved anxieties.

\section{Increased professional engagement}

Both groups of students described adopting a keener attitude to their placement during their assistantship than previously. This was often reflected through a commitment to on-call shifts. The incentive for increased engagement for those in the aligned group included the desire to satisfy their team, whereas for those in the misaligned group, this was motivated by the fear of their future responsibilities. Many supervisors also perceived that students were more engaged during the assistantship than in other medical school placements, particularly if their assistantship was aligned to their first F1 post:

I think for me the reality, sort of, strikes you in this placement. I think you kind of see things, 'oh this is the job I'm actually going to be doing' and therefore you are doing your best. Whereas maybe in previous years you kind of skive off a little bit, but you'd don't tell them about that. (M_S_Aligned_31)

\section{Identity classification and performing identities}

Concerning students' perceived identities, classifications given by students and supervisors most commonly involved phrases such as F0 or F1 without the signature. This observation was consistent between both groups of students:
I'm an FY0. Yes, I would say somewhere in between. I would never say I'm a doctor now because I'm still a student, but I feel like you do have a lot more responsibility at this stage than you did six months ago. (F_S_Misaligned_9)

More rarely, students from both groups described performing multiple identities. In these narratives, students described choosing when to wear their 'masks', selectively reverting to their medical student identity to avoid responsibility in certain situations:

It was great and when I'm in CDU [Clinical Decisions Unit] I feel like an F1 as well because you clerk, present, do jobs, but on the days where we're really full I feel like 'I'm a medical student'. (F_S_Misaligned_24)

Like going off about the ward because in one aspect it's nice to like actually feel like a real part of the team, like you're actually a doctor and you're doing some good, but then you're brought back down to earth when the nurse comes over to you and he says 'doctor, doctor we need a dose of warfarin' and you, sort of, have to go off and say, 'sorry I can't do that'. (M_S_Aligned_4)

\section{Tolerating uncertainty}

A few students described how their insight into their own limitations had developed during the assistantship, especially those in the aligned group. Through realising that even competent junior doctors have a limit to their capabilities, students began to accept that having limitations to their knowledge was normal, understanding that learning is a continuous process. A minority of students even revealed that they had adopted their supervising doctors as role models:

The more you hang out with the $\mathrm{F} 1$ the more you realise they're on their phone looking it up. That's really nice to see. You don't have to remember all of it. (F_S_Aligned_36)

\section{Unrelieved anxieties}

Some students conveyed feeling unprepared for aspects of an F1's role. While many students in the misaligned group reported anxieties about entering an unfamiliar workplace, many in the aligned group were anxious in the knowledge of the demands that lay ahead. Some foundation doctor supervisors drew on their own assistantship experience to remark that a certain degree of anxiety always remains before starting work. Extremely rarely, students revealed that the assistantship had led to their disillusionment from clinical practice. Such comments were from students who had experienced organisational barriers during their assistantship:

In some ways I'm more anxious about starting at the end of this placement because I know how busy the job is. (F_S_Aligned_28) 


\section{DISCUSSION}

The perceptions of students and supervisors in this study reinforce the findings of previous work, affirming the value of student assistantships generally in terms of a perceived increase in preparedness for practice. ${ }^{22-25}$ Students and supervisors reported that students become functional members of their team during their assistantship. Through undertaking the duties of an F1 doctor, students reported developing confidence in their ability to complete tasks independently and increasing skills transferable to a variety of work settings. Nevertheless, like previous work, our study has demonstrated the variability in student experiences on assistantship placements. ${ }^{9}{ }^{23-25}$ Unlike other studies, ${ }^{24}$ the majority of participants in our study reported students having the opportunity to complete tasks independently under appropriate supervision, suggesting that these assistantships provide a realistic preparation for the demands of being an F1. However, the accounts of consultants being unwilling for students to undertake routine tasks undertaken by an F1 doctor suggest a need to address a lack of awareness of the assistantships' aims among senior clinicians. In addition, some participating consultants conveyed that students were sometimes reluctant to take on increased levels of responsibility. Although consultants may see a limited snapshot of students' day-to-day activities, these observations suggest a need to better define the aims of assistantships and establish the duties of the prospective F1s. ${ }^{30}$ 31 With patient safety of primary importance, it is also important to ensure that students are adequately supervised at all times. Although rare, examples of students having to fill in the role of their F1 suggest a need to remind clinical teams that appropriate supervision should be arranged for students when F1 doctors are absent.

While students in different hospitals experienced a varying degree of structured (classroom) teaching within a period of unstructured (ward-based) learning, following the F1 was naturally seen as the crucial part of the assistantship. Students valued having most of their time free to focus on 'learning the trade'. Nevertheless, prescribing teaching sessions and the opportunity to shadow-prescribe were highly valued by students in increasing their confidence in this important domain. ${ }^{25}$ This is noteworthy given that this is an identified area of weakness in new doctors. ${ }^{9} 15$ The care of acutely unwell patients is another area in which medical graduates are known to be underprepared ${ }^{9} 101516$ and has been highlighted as an important learning opportunity for inclusion in student assistantships. ${ }^{30} 31$ However, significantly, the scarcity of acute care experience remains a notable gap with potentially significant consequences on levels of trainee anxiety. ${ }^{25}$ Consequently, many students expressed that they would welcome interventions to address their anxieties in this area.

Owing to the unique context of this study and the way in which we analysed our data, we have been able to untangle differences between assistantships that are aligned and those that are not. As such, our results suggest that undertaking an assistantship aligned with one's first F1 post provides additional benefits that enhance feelings of preparedness. F1 post alignment positively affected students' engagement with their placement and supervisors' interactions with their students. Students and participating F1 doctors described how opportunities for workplace acclimatisation during this period had served to reduce their anxieties about starting work. Prior exposure to local systems, practice and protocols has the potential to positively affect patient safety during the August transition period. Conversely, those who undertook a misaligned assistantship generally felt disadvantaged and almost all students and supervisors reported that this limited the utility of their experience. While these students remained engaged in the assistantship placement, for many, this was motivated by the desire to reduce their anxieties about their clinical competencies.

Previous qualitative studies have suggested that students feel that assistantships are less useful if attached to units that are less related to where they would start work $^{24}$ or that students who are due to start work in different geographical areas to their assistantship feel disadvantaged. ${ }^{25}$ However, these studies did not thoroughly contrast the differences between students who were aligned or misaligned to their first jobs or include narrative interviews with supervisors. ${ }^{24}{ }^{25}$ This study is the first (to the best of our knowledge) to explore the potential added value of alignment by comparing the views of both students who were aligned and misaligned to their first jobs, in addition to the view of supervisors. Overall, we have found that students whose assistantship was aligned to their first junior doctor post are perceived to benefit more from the assistantship than those who were not aligned, from the perspective of students and supervisors. Concurrently, most students in misaligned placements felt disadvantaged compared to those who completed their assistantship in the setting of their prospective jobs.

\section{Limitations and strengths of the study}

This study has a number of limitations. First is the use of convenience sampling. This self-selected sample may have represented the more engaged and motivated members of the student year group and of supervisor participants. Therefore, the results, and the conclusions drawn from these participants, might not be applicable to the entire national student cohort or supervisor group. Despite this limitation, this study design permitted the recruitment of a large sample comprising four participant groups across two medical schools in a single country (total $n=66$ ), far greater than previous qualitative studies investigating assistantship experiences. ${ }^{24} 25$ Recruitment of a large sample facilitated the comparison of aligned assistantship versus misaligned assistantship experiences. The use of snowballing among foundation doctor and consultant doctor supervisors 
enabled additional perspectives of assistantship experiences to be gained. Furthermore, students and supervisors were based at 10 different hospital sites across Wales which included a mix of Tertiary Centres, District General Hospitals and Specialist Community Units (eg, Community Psychiatric Units). The data collected on this model of assistantship are therefore applicable across a range of clinical contexts.

Another limitation of this study is that we have only reported on participants' experiences of assistantships and perceived future benefits, rather than actual benefits during F1 posts. This is because all interviews were held at the end of the assistantship period prior to the beginning of the F1 period. However, this purposive timing afforded participants sufficient opportunity for reflection on their experiences while minimising the potential for recall bias.

\section{Implications of the study}

The GMC's most recent curriculum guidance recommends that assistantships should be long enough for students to become part of the clinical team. ${ }^{20}$ Irrespective of alignment, our results convey that a longitudinal model of 6-week to 7-week duration was generally sufficient for students to become functionally integrated into their team. However, to enable students to focus on their first $\mathrm{F} 1$ post and gain the most from their experience, we support the suggestion that teaching sessions should be minimised, and relate to areas that cause the most anxiety, such as prescribing and acute care. ${ }^{25}$ Furthermore, to ensure that all students are given adequate levels of responsibility and are fully integrated into their team, it may be beneficial for medical schools to take action in order to increase the awareness of consultant supervisors and other healthcare staff of the aims of student assistantships. Clarifying the expected learning outcomes of student assistantships may also ensure that students and clinicians have a shared understanding so that students may be more likely to take the initiative without unnecessary restriction.

It is also important to ensure that students gain adequate experience in important clinical areas. ${ }^{30} 31$ To overcome students' continued anxieties surrounding acute care, assistantships should seek to include discrete opportunities for exposure to the care of critically ill patients. As an example, the opportunity to carry the cardiac arrest bleep was highly valued by students in one hospital. In addition, the recent requirement for assistantships to 'include exposure to out-of-hours on-call work' may help to increase students' exposure to this area. ${ }^{20}$ Such clinical experience could be enhanced by ensuring that advanced life support training is purposefully timed before graduation. Such interventions could ensure that all students are adequately prepared for the important demand of managing critically unwell patients as F1 doctors.

Finally, the findings of our study suggest that aligning the placement with students' first F1 post can enhance the perceived value that student assistantships have during the assistantship itself. Lightman $e t a \ell^{25}$ previously proposed a UK-wide programme that enables all students to undertake an assistantship in the setting of their prospective F1 jobs. ${ }^{25}$ However, the evidence presented to support this proposal did not consider supervisors' views or highlight specific differences between the views of students in aligned and misaligned placements. ${ }^{25}$ By thoroughly comparing interviews with aligned and misaligned students and their supervisors, we conclude that students in aligned placements are perceived to benefit from the opportunity to become familiar with their future working environment. As a result, our study can be seen as providing support for the proposal for a programme enabling all students in the UK to undertake an assistantship in the setting of their prospective F1 jobs before graduation. However, given that there is little evidence to date that demonstrates potential benefits beyond the specific time of assistantships, we would argue that further research is needed before such a radical programme of change is recommended. Indeed, such an arrangement would require an enhanced collaboration between undergraduate and postgraduate stakeholders nationwide. In addition, barriers to overcome include the variation in the timing and duration of student assistantship within the final-year programmes of different medical schools. Alternatively, given that students are unable to undertake many of the duties of a doctor during their assistantship due to lack of GMC registration, implementing an extended 'shadowing period' may be an alternative solution to increasing preparedness for practice. Such a period of supervised acclimatisation to the workplace following graduation may maximise the extent of prospective doctors' preparedness for employment. However, it is likely that this solution would be met by similar organisational barriers to those already discussed, in addition to the extra cost implications as shadowing occurs post graduation.

\section{Opportunities for further research}

Given the lack of evidence regarding the efficacy of aligned versus misaligned assistantships, we believe that future research should comprise a longitudinal qualitative and quantitative investigation spanning into the F1. Such a study would therefore involve follow-up interviews post graduation while participants are working as junior doctors. Furthermore, questionnaires drawing on a larger group of students should be administered across the undergraduate-postgraduate transition period, examining whether aligning assistantships with their first F1 post has any impact on participants' well-being (eg, stress, anxiety and burnout). Without such evidence, it might be difficult to justify a nationwide drive towards full assistantship-F1 alignment.

Acknowledgements The authors would like to thank Dr Wyn Harris, Dr Steve Riley, Dr Anton Saayman and Mr Michael Stechman for their support.

Contributors LVM and AB conceived the idea and designed the study. LVM and SEW obtained institutional ethical approval for the study. OMJ and CO 
were responsible for participant recruitment and data collection under the supervision of $L V M$ and $A B$. OMJ, CO, AB and LVM were involved in the development of the thematic framework and subsequent data analysis. SEW assisted $\mathrm{OMJ}$ and $\mathrm{CO}$ at the data coding stage. $\mathrm{OMJ}$ and $\mathrm{CO}$ drafted the manuscript. All authors reviewed and revised the manuscript and all authors approved the final version.

Funding This research was funded from an Association for the Study of Medical Education small grant.

Competing interests None declared.

Ethics approval Ethical approval was granted by the School of Medicine Research Ethics Committee, Cardiff University, Wales, in February 2015.

Provenance and peer review Not commissioned; externally peer reviewed.

Data sharing statement The raw data for this research consist of audio-recordings of narrative interviews conducted between 1 and 26 June 2015. This comprises the first set of interviews within a longitudinal programme of mixed-methods research. The principle investigator (LVM) and researchers (OMJ, CO and SEW) have access to this specific data set, including audio-recordings of interviews and interview transcripts, in addition to participant contact details and signed consent forms. All authors (LVM, $\mathrm{OMJ}, \mathrm{CO}$, SEW and $\mathrm{AB}$ ) have access to anonymised data from this set. All data are stored securely and on password-protected and encrypted computers. No further publications from these data are available at present, but due to the longitudinal nature of the research, further work is anticipated. Participants have not given their permission for data sharing outside of the research group. Thus, no additional data are available.

Open Access This is an Open Access article distributed in accordance with the Creative Commons Attribution Non Commercial (CC BY-NC 4.0) license, which permits others to distribute, remix, adapt, build upon this work noncommercially, and license their derivative works on different terms, provided the original work is properly cited and the use is non-commercial. See: http:// creativecommons.org/licenses/by-nc/4.0/

\section{REFERENCES}

1. Smith R. Thousands of juniors start jobs in NHS 'killing season'. Telegraph 2012 2012-08-01. http://www.telegraph.co.uk/news/health/ news/9441885/Thousands-of-juniors-start-jobs-in-NHS-killingseason.html (accessed 5 Jun 2016).

2. Vaughan L, McAlister G, Bell D. 'August is always a nightmare': results of the Royal College of physicians of Edinburgh and society of acute medicine august transition survey. Clin Med (Lond) 2011;11:322-6.

3. Jen $\mathrm{MH}$, Bottle A, Majeed A, et al. Early in-hospital mortality following trainee doctors' first day at work. PLoS One 2009;4:e7103.

4. Young JQ, Ranji SR, Wachter RM, et al. "July effect": impact of the academic year-end changeover on patient outcomes: a systematic review. Ann Intern Med 2011;155:309-15.

5. Phillips DP, Barker GE. A July spike in fatal medication errors: a possible effect of new medical residents. J Gen Intern Med 2010;25:774-9.

6. Yaghoubian A, de Virgilio C, Chiu V, et al. "July effect" and appendicitis. J Surg Educ 2010;67:157-60.

7. Inaba K, Recinos G, Teixeira PG, et al. Complications and death at the start of the new academic year: is there a July phenomenon? J Trauma 2010;68:19-22.

8. Kellett J, Papageorgiou A, Cavenagh P, et al. The preparedness of newly qualified doctors-Views of Foundation doctors and supervisors. Med Teach 2015;37:949-54.
9. Monrouxe L, Bullock AC, Gormley J, et al. How prepared are UK medical graduates for practice? UK: General Medical Council, 2014.

10. Tallentire VR, Smith SE, Wylde K, et al. Are medical graduates ready to face the challenges of Foundation training? Postgrad Med $J$ 2011;87:590-5.

11. Goldacre MJ, Lambert TW, Svirko E. Foundation doctors' views on whether their medical school prepared them well for work: UK graduates of 2008 and 2009. Postgrad Med J 2014;90: 63-8.

12. Morrow G, Johnson N, Burford B, et al. Preparedness for practice: the perceptions of medical graduates and clinical teams. Med Teach 2012;34:123-35.

13. Matheson C, Matheson D. How well prepared are medical students for their first year as doctors? The views of consultants and specialist registrars in two teaching hospitals. Postgrad Med $\mathrm{J}$ 2009;85:582-9.

14. GMC. National training survey 2011. UK: General Medical Council, 2011.

15. Illing J, Morrow G, Kergon C, et al. How prepared are medical graduates to begin practice? A comparison of three diverse UK medical schools. Final report to GMC April 2008, 2008:18-9.

16. Tallentire VR, Smith SE, Skinner J, et al. The preparedness of UK graduates in acute care: a systematic literature review. Postgrad Med J 2012;88:365-71.

17. Illing JC, Morrow GM, nee Kergon CR, et al. Perceptions of UK medical graduates' preparedness for practice: a multi-centre qualitative study reflecting the importance of learning on the job. BMC Med Educ 2013;13:34.

18. Sen Gupta T, Hays R, Woolley T, et al. Workplace immersion in the final year of an undergraduate medicine course: the views of final year students and recent graduates. Med Teach 2014;36: 518-26.

19. GMC. Tomorrow's doctors outcomes and standards for medical education. London, UK: General Medical Council, 2009:55.

20. GMC. Promoting excellence: standards for medical education and training. London, UK: General Medical Council, 2015.

21. GMC. Be prepared: are new doctors safe to practise? Manchester UK: General Medical Council, 2014.

22. Braniff C, Spence RA, Stevenson M, et al. Assistantship improves medical students' perception of their preparedness for starting work. Med Teach 2016;38:51-8.

23. Burford $B$, Ellis $E$, Williamson $A$, et al. Learning opportunities in 'student assistantships'. Clin Teach 2015;12:121-7.

24. Fullbrook A, Ross M, Mellanby E, et al. Initial experiences of a student assistantship. Clin Teach 2015;12:310-14.

25. Lightman E, Kingdon S, Nelson M. A prolonged assistantship for final-year students. Clin Teach 2015;12:115-20.

26. Van Hamel C, Jenner L. Prepared for practice? A national survey of UK foundation doctors and their supervisors. Med Teach 2015;37:181-8.

27. British Medical Association. Induction, shadowing and student assistantships. London, UK: BMA. http://www.bma.org.uk/ support-at-work/contracts/juniors-contracts/assistantships-shadowingand-induction (accessed 12 Dec 2015).

28. Lambert T, Goldacre M. Career choices and career destinations of Welsh medical graduates a report for the Welsh postgraduate deanery. Oxford: UK Medical Careers Research Group, 2009. http://www.walesdeanery.org/images/stories/Files/Documents/ careers/Welsh_Graduates_Report_Draft_250809.pdf (accessed 15 Oct 2015)

29. Ritchie J, Spencer L. Qualitative data analysis for applied policy research. In: Bryman A, Burgess RG, eds. Analyzing qualitative data. London: Routledge, 2002:305-30.

30. Vivekananda-Schmidt P, Crossley J, Bax N. Student doctors taking responsibility. Clin Teach 2011;8:267-71.

31. Tallentire VR, Smith SE, Cameron HS. Designing a purposefu student assistantship. Clin Teach 2012;9:210-15. 